\title{
Recurrent visual loss in homozygous sickle cell disease
}

\author{
P I CONDON, R A F WHITELOCKE, A C BIRD, J F TALBOT, \\ AND G R SERJEANT
}

From the Medical Research Council Laboratories (Jamaica), University of the West Indies, Kingston, Jamaica

SUMMARY In sickle cell retinopathy vascular involvement is most frequently recognised at the retinal periphery, but obstruction of perimacular arterioles and of major retinal vessels may also occur. This report describes a patient with homozygous sickle cell (SS) disease with recurrent occlusion of major retinal vessels associated with recurring transient impairment of visual function.

The vaso-occlusive process in sickle cell disease may result in both transient and permanent occlusion of retinal vessels. Although vascular involvement is most frequently recognised at the retinal periphery, obstruction of perimacular arterioles ${ }^{12}$ and of major retinal vessels ${ }^{3-6}$ may also occur. Asdourian et al.' described remodelling of blood vessels in the perimacular region, which they attributed to arteriolar obstruction, but there was no consistent pattern of associated visual loss. Occlusion of major retinal arterioles in the perimacular region was associated with visual impairment in a patient with sickle cell-haemoglobin C (SC) disease, ${ }^{\circ}$ and the Correspondence to $\mathrm{Mr} \mathrm{R}$ Whitelocke, FRCS, Department of Ophthalmology, St Bartholomew’s Hospital, London EC1.

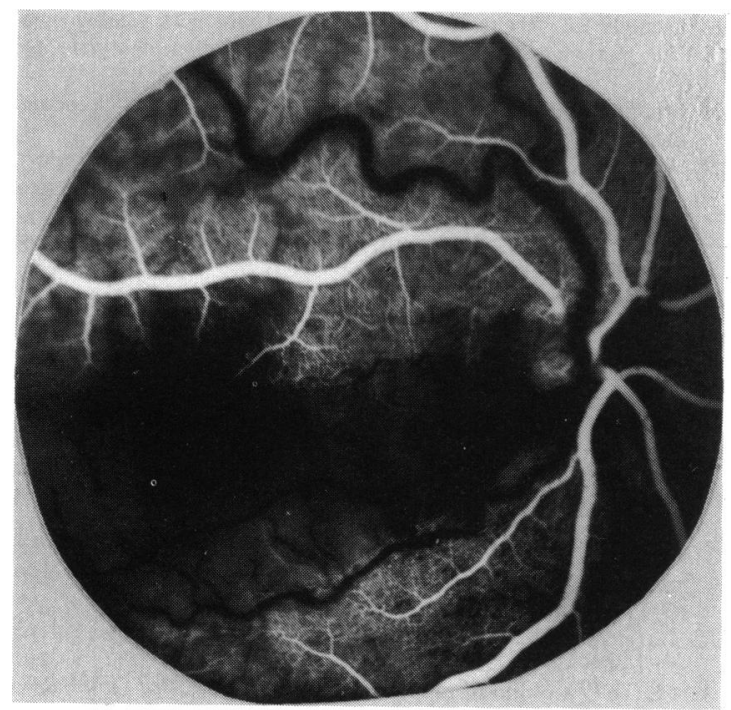

Fig. 1a vessels remained non-perfused during the period of observation. The present report describes a patient with homozygous sickle cell (SS) disease with recurrent occlusion of major retinal vessels associated with recurring but transient impairment of visual function.

\section{Case report}

This 20-year-old male patient with SS disease attended the sickle cell clinic at the University Hospital of the West Indies. The diagnosis of SS disease was based on standard criteria including a single major haemoglobin band in the position of $\mathrm{HbS}$ on alkali and acid haemoglobin electrophoresis, a positive sickling test, and compatible $\mathrm{HbA}_{2}$ levels.

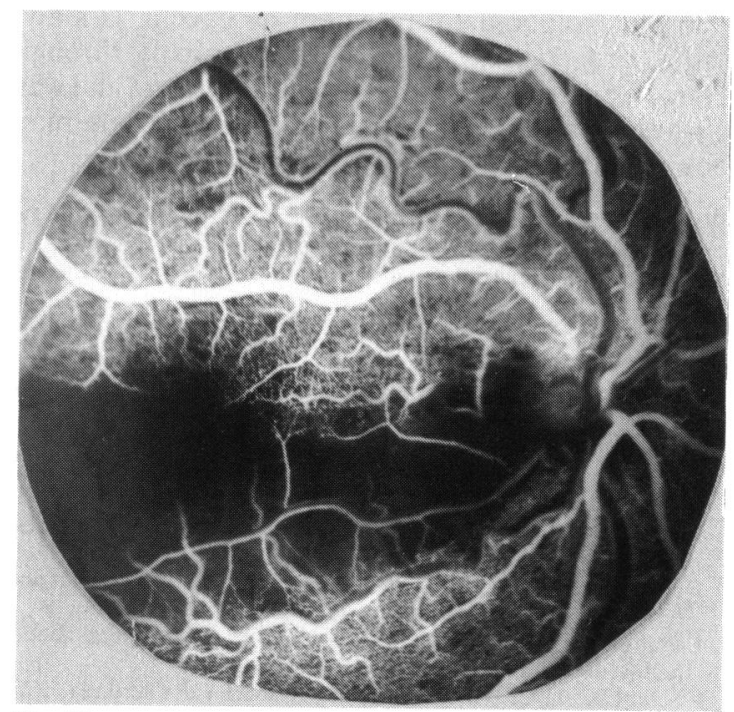

Fig. 1b 




Fig. 1c

Fig. 1 Fluorescein angiogram of right eye on 21 July 1981. (a) Early arterial phase showing non-perfusion of the inferotemporal arteriole from the disc margin and loss of associated capillary perfusion. (b) Early venous phase showing retrograde filling of inferotemporal arteriole. (c) Late phase showing vessel filling from the optic disc but a non-perfused venous tributary.

Average steady state haematological values over the past five years were as follows: $\mathrm{HbF} 4 \cdot 5 \%, \mathrm{HbA}_{2}$ $3.2 \%$, Hb $7.2 \mathrm{~g} / \mathrm{dl}, \mathrm{PCV} 19.4 \%$, MCHC $37.8 \mathrm{~g} / \mathrm{dl}$, RBC $2 \cdot 12 \times 10^{12} / 1$, MCV $91 \mathrm{fl}, \mathrm{MCH} 33 \mathrm{pg}$, reticulocytes $13 \%$, Platelets $463 \times 10 \%$, irreversibly sickled cells $15 \%$, bilirubin direct reacting $1.2 \mathrm{mg} / \mathrm{dl}$, total $9.4 \mathrm{mg} / \mathrm{dl}$.

On the morning of 21 July 1981 he awoke with a dense central scotoma in the right eye, and the visual acuity was reduced to counting fingers but was normal in the left eye. Ophthalmoscopy revealed the right inferotemporal retinal arteriole to be narrowed, with retinal pallor and a cherry-red (dark) spot at the fovea. Fluorescein angiography confirmed nonperfusion of this vessel from the optic disc in the early arterial phase (Fig. 1a), but the early venous phase showed retrograde filling of this arteriole (Fig. 1b), and the late phase indicated some filling of the arteriole from the optic disc (Fig. 1c). There was a large non-perfused zone in the inferotemporal venous tributary.

Over the next 24 hours visual acuity improved rapidly and was normal two weeks later, though the patient had a small paracentral scotoma. On ophthalmoscopy the inferotemporal arteriole was slightly narrowed, with persistent but less marked retinal pallor, and there was a triangular superficial haemorrhage lateral to the optic disc. The inferotemporal arteriole filled normally on angiography (Fig. 2), and perfusion was restored in branches of the inferotemporal vein, though a perifoveal avascular zone (PAZ) persisted inferolaterally to the macula. 
Fig. 2 Angiogram on 4 August 1981. Perifoveal avascular zone marked by arrow.

Fig. 3 Angiogram on 2 February 1982. There is non-perfusion of the inferotemporal retinal arteriole inferior to the macula and loss of associated retinal perfusion.
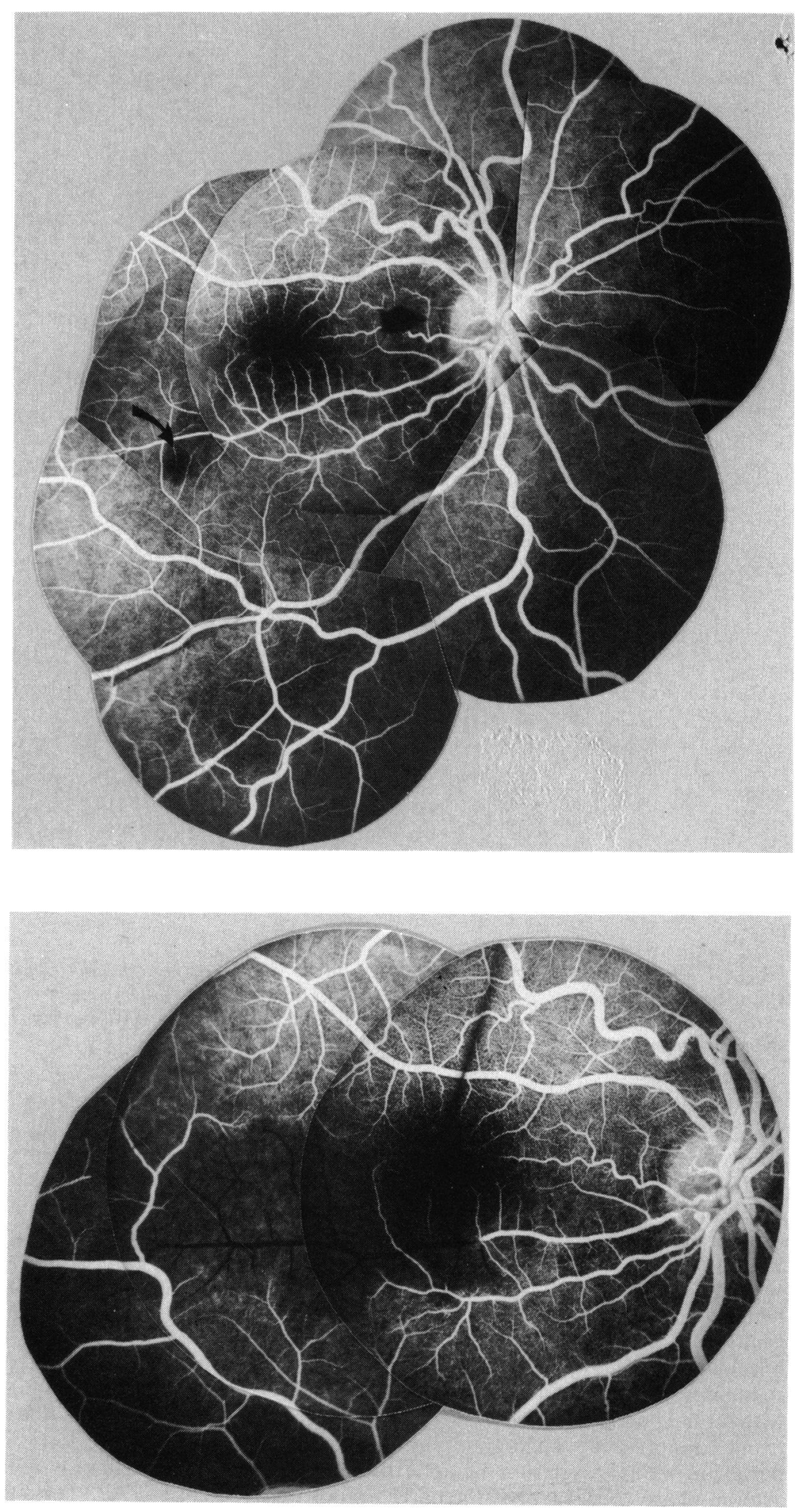


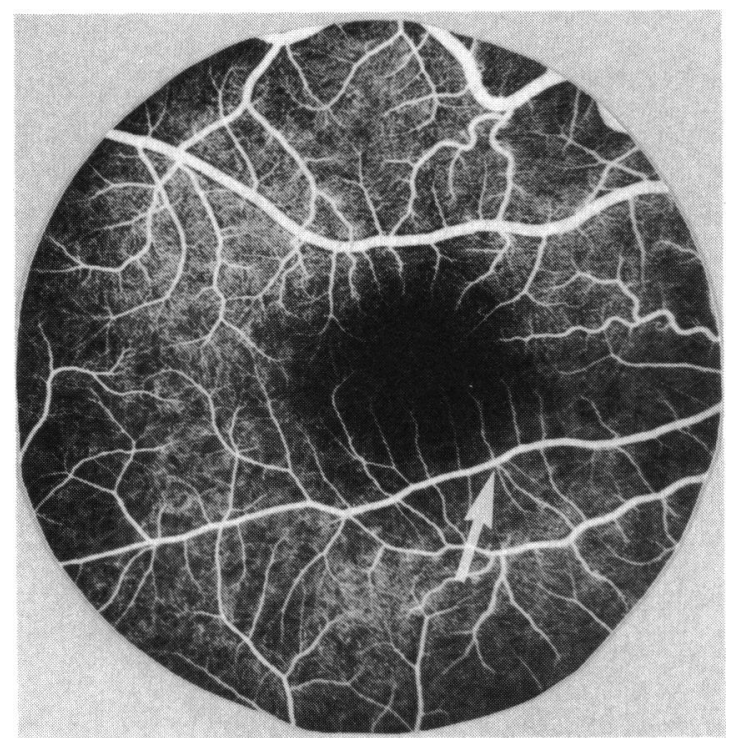

Fig. 4 Angiogram of same area as in Fig. 3 on 20 September 1982 showing that perfusion has been re-established. Site of previous block indicated by white arrow.

Seven months after the original episode the patient was asymptomatic, with normal visual acuity, but another obstruction of the inferotemporal retinal arteriole inferior to the macula and a corresponding area of retinal non-perfusion were apparent (Fig. 3). Seven months later he was asymptomatic, with normal visual acuity, and angiography showed normal filling of the inferotemporal retinal arteriole and remodelling of the perifoveal capillary network (Fig. 4). Eighteen months after the original episode, and while working exposed in cold weather at 4000 feet $(1220 \mathrm{~m})$, he lost vision in the right eye. On examination the visual acuity was $6 / 24$, and there was cloudy swelling in the macular area with cotton wool spots at the posterior pole. Angiography revealed non-perfusion of branches of the supero- and inferotemporal retinal arterioles distal to the macula, with corresponding areas of capillary non-perfusion (Fig. 5). On the next day some flow had returned, though there was persistent non-perfusion of a major branch of the superotemporal retinal arteriole and of a minor branch of the inferotemporal arteriole (Fig. 6). One week later visual acuity was normal, though the affected branch of the superotemporal vessel remained non-perfused (Fig. 7). Three weeks later angiography indicated occlusion of a major branch of the superotemporal vessel at a more distal site, and there was evidence of collateral circulation from more temporal peripheral vessels, though the block in the branch of the inferotemporal arteriole had resolved (Fig. 8).

\section{Discussion}

Occlusion of the central retinal artery or its major branches in sickle cell disease may occur spontaneously $^{35}$ or following retrobulbar anaesthesia. ${ }^{78}$ The remodelling of the perimacular vasculature that attends occlusion of smaller arterial branches has

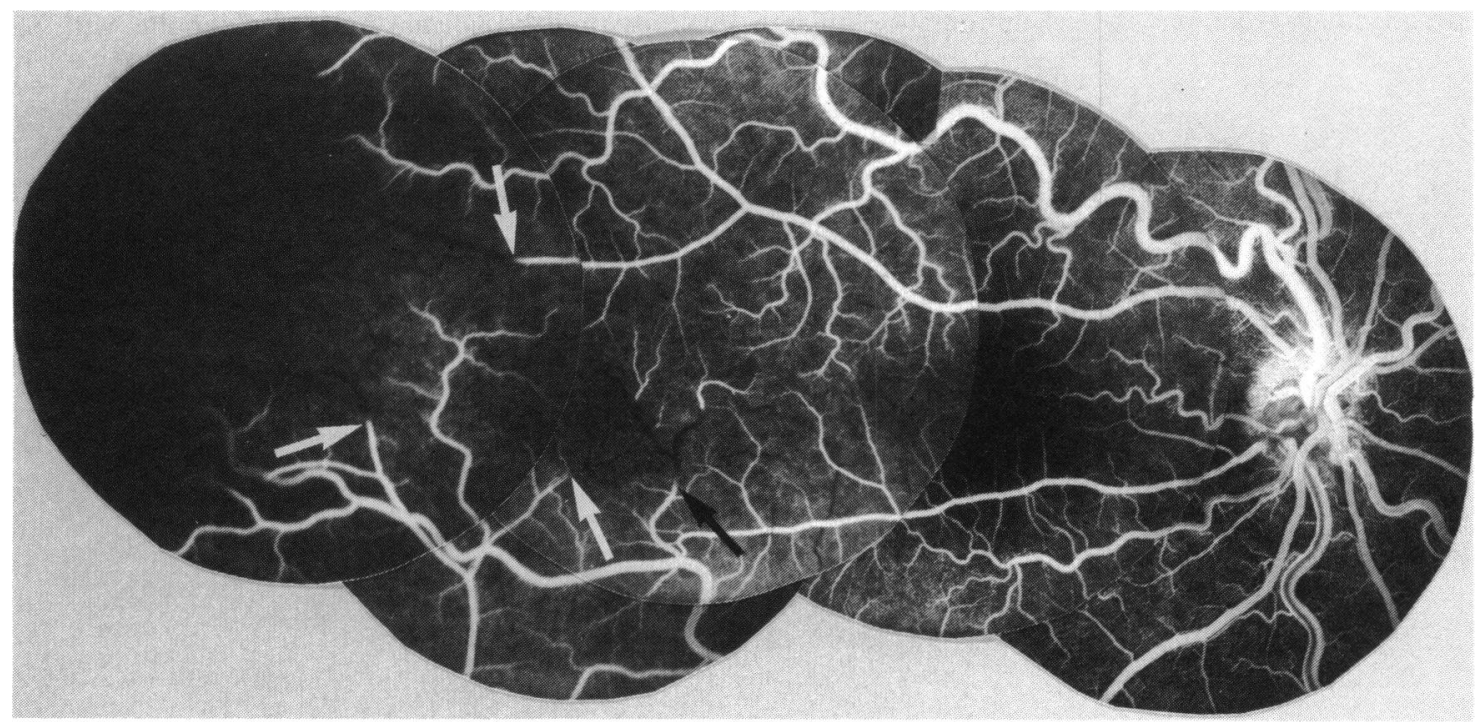

Fig. 5 Angiogram on 31 January 1983 shows non-perfusion of supero- and inferotemporal arterioles lateral to the macula (white arrows) and venous non-perfusion (black arrow). 


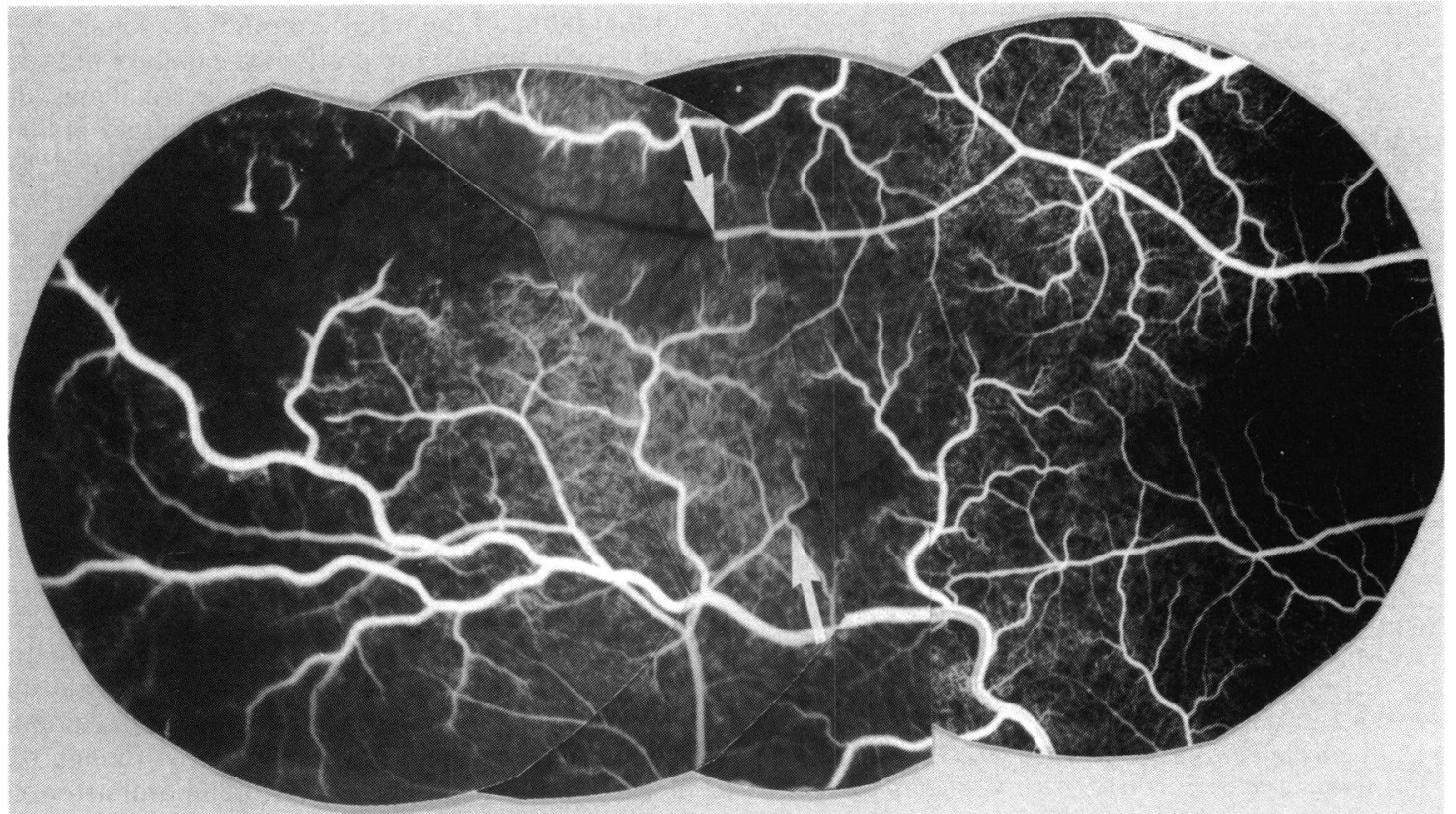

Fig. 6 Angiogram on 1 February 1983 shows that only two sites of arterial non-perfusion (white arrows) persist.

been well reviewed.' The precipitating factors for such occlusive episodes are unknown, though the simultaneous involvement of multiple sites suggested to Chopdar $^{6}$ that the probable mechanism was embolism from sickling elsewhere in the body.

The frequency of such occlusive episodes is unknown, as small branch arteriolar occlusion in the perimacular area may be asymptomatic,' though occlusions of larger branches are generally associated with visual symptoms. The observation that this was the only patient with such symptoms among a group of approximately 800 adults with SS disease and 300 adults with $\mathrm{SC}$ disease suggests that this is an unusual occurrence. The reasons for the arterial occlusions in this patient are unclear. Most haematological indices were within the normal range for patients with SS
Fig. 7 Angiogramon 8 Februrary 1983 shows non-perfusion of the superotemporal arteriole more proximally (upper arrow) than in the previous week and a new block of inferotemporal arteriole (lower arrow).

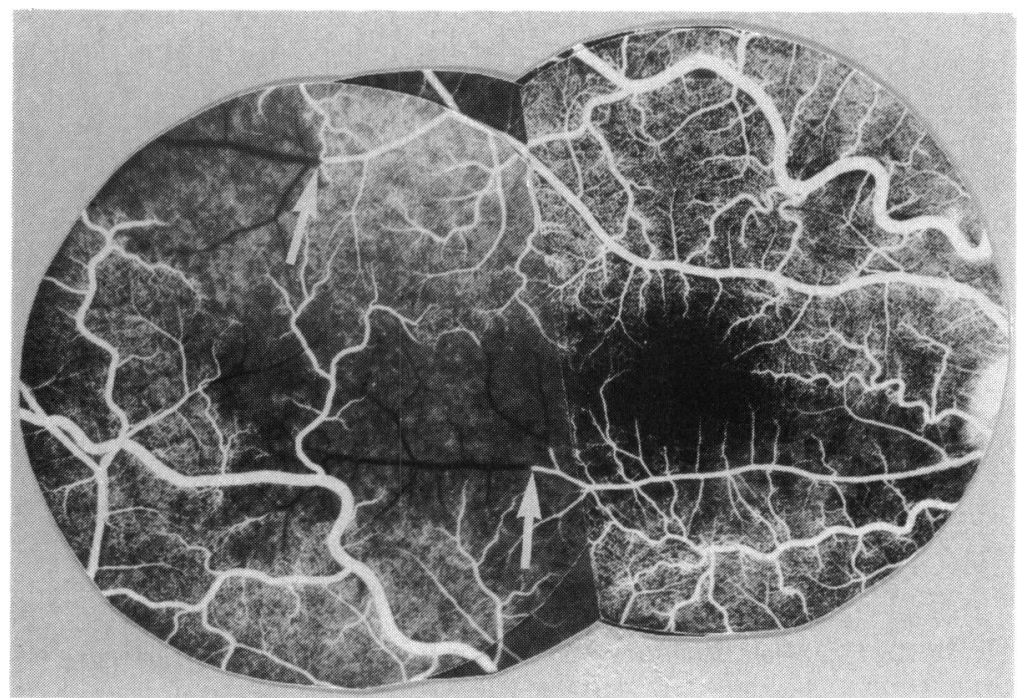




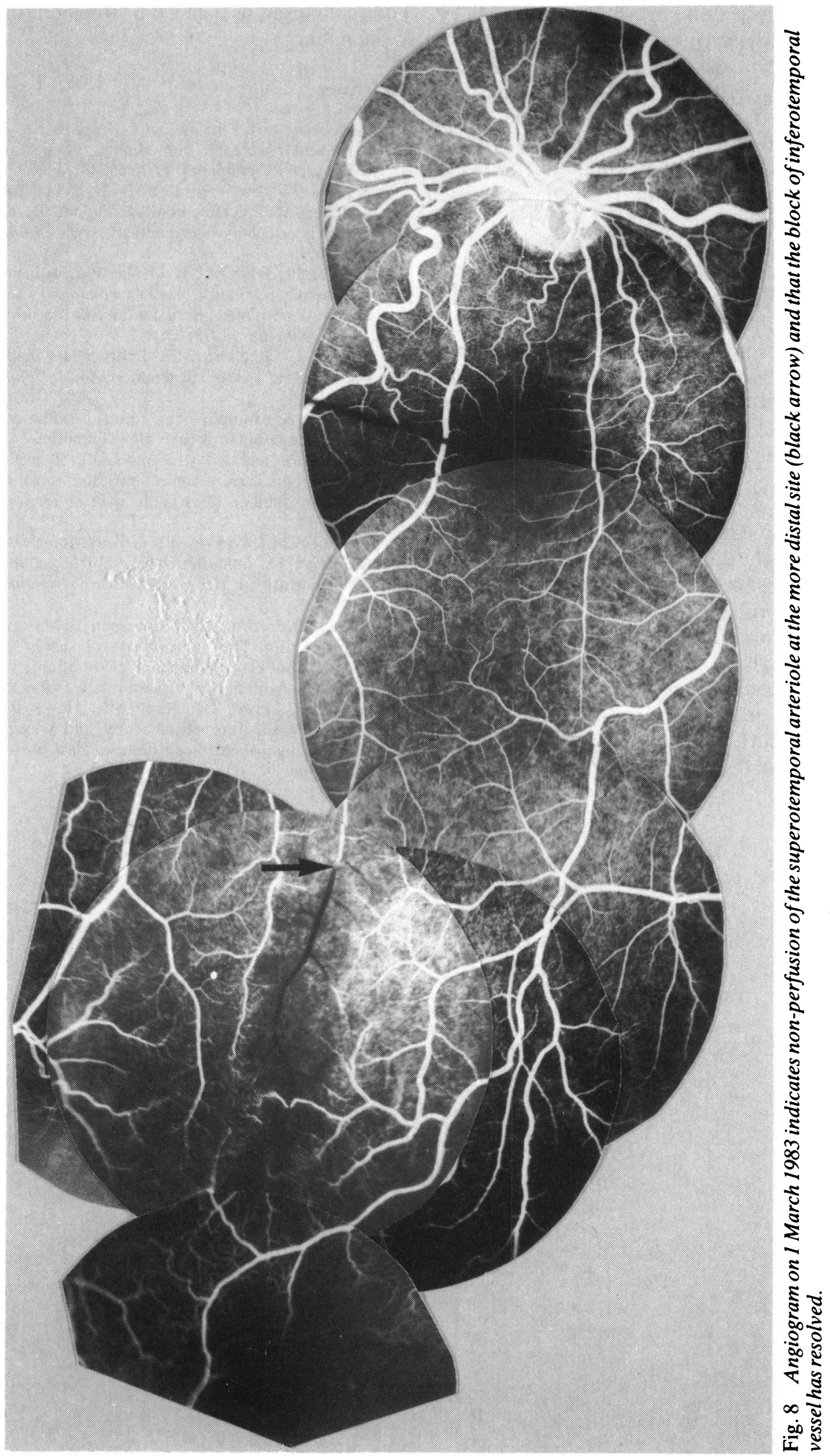


disease of the same sex and age, ${ }^{9}$ though the MCHC was close to the 95 th percentile and the total bilirubin level above it. The mean cell haemoglobin concentration, computed from the centrifuged haematocrit, was $39 \mathrm{~g} / \mathrm{dl}$ on the day of the original episode, raising the possibility that cells of a high internal viscosity and consequently lowered deformability had compromised the retinal circulation. It is well recognised that the red cells in patients with SS disease are markedly heterogenous, and there is increasing interest in the pathological significance of the dense cell fraction. Although direct measurements of dense cells are not available in this patient, the high $\mathrm{MCHC}$ indirectly indicates an increased dense cell fraction. There were no obvious precipitating factors of the initial episode, but the second symptomatic episode occurred while the patient was working at altitude under cold conditions, both factors known to favour sickling.

Vessel involvement at the posterior pole in sickle cell disease presents a spectrum ranging from central retinal artery occlusion, major branch occlusion, minor branch occlusion, to perimacular capillary drop-out and formation of perifoveal avascular zones. The last are frequently asymptomatic and without reduced visual acuity, ${ }^{10}$ and impairment of vision generally becomes more marked with involvement of the larger vessels. The present case illustrates the transient nature of some occlusions of larger vessels in sickle cell disease, and this condition should be recognised as a cause of transient or intermittent visual loss.

\section{References}

1 Asdourian GK, Nagpal KC, Busse B, et al. Macular and perimacular vascular remodelling in sickling haemoglobinpathies. BrJ Ophthalmol 1976; 60: 431-53.

2 Stevens TS, Busse B, Lee C-B, Woolf MB, Galinos SO, Goldberg MF. Sickling hemoglobinopathies. Macular and perimacular vascular abnormalities. Arch Ophthalmol 1974; 92: 455-63.

3 Condon PI, Serjeant GR. Ocular findings in homozygous sickle cell anemia in Jamaica. Am J Ophthalmol 1972: 73: 533-43.

$4 \mathrm{Knapp} \mathrm{JW}$. Isolated macular infarction in sickle cell (SS) disease. Am J Ophthalmol 1972: 73: 857-9.

5 Acacio I, Goldberg MF. Peripapillary and macular vessel occlusions in sickle cell anemia. Am J Ophthalmol 1973; 75: $861-6$.

6 Chopdar A. Multiple major retinal vascular occlusions in sickle cell haemoglobin C disease. Br J Ophthalmol 1975; 59: 493-6.

7 Klein ML, Jampol LM, Condon PI, Rice TA, Serjeant GR. Central retinal artery occlusion without retrobulbar hemorrhage after retrobulbar anesthesia. Am J Ophthalmol 1982; 93: $573-7$.

8 Jampol LM, Condon PI, Dizon-Moore R, Serjeant GR, Schulman JA. Salmon-patch hemorrhages after central retinal artery occlusion in sickle cell disease. Arch Ophthalmol 1981; 99: 237-40.

9 Hayes RJ, Beckford M, Grandison Y, Mason K, Serjeant BE, Serjeant GR. The haematology of steady state homozygous sickle cell disease. Frequency distributions, variation with age and sex, longitudinal observations. Br J Haematol in press.

10 Marsh RJ, Ford SM, Rabb MF, Hayes RJ, Serjeant GR. Macular vasculature, visual acuity, and irreversibly sickled cells in homozygous sickle cell disease. Br J Ophthalmol 1982; 66: $155-60$. 